\title{
Tarefas para a aprendizagem de professores que ensinam matemática nos anos iniciais
}

\author{
Tasks for learning teachers who teach mathematics in the elementary school \\ Lilian Cristina de Souza Barboza ${ }^{1}$ \\ Vinícius Pazuch ${ }^{2}$ \\ Alessandro Jacques Ribeiro ${ }^{3}$
}

\begin{abstract}
Resumo
O uso de tarefas para a aprendizagem de professores é um tema de fundamental importância para investigação na formação de professores. Assim, objetivou-se neste artigo, compreender e explicar como ocorre a construção do conhecimento matemático e didático de professores que ensinam matemática nos anos iniciais em um processo formativo sobre os diferentes significados do sinal de igualdade. A pesquisa é qualitativainterpretativa e os dados, documentais e em áudio, são provenientes de um processo formativo desenvolvido com 6 professoras de uma escola municipal de São Paulo. As análises mostraram a mobilização, a reorganização e a construção de conhecimentos matemáticos e didáticos por parte das professoras que, coletivamente, planejaram e desenvolveram uma aula de matemática contemplando o sinal de igualdade e, posteriormente, refletiram sobre ela. Entende-se que tais movimentos se deram por intermédio do uso das tarefas de aprendizagem profissional e pelas mediações da formadora.
\end{abstract}

Palavras-chave: Formação continuada; Pensamento algébrico; Sinal de igualdade; Conhecimentos matemáticos e didáticos.

\begin{abstract}
Using tasks for teacher learning is a fundamentally topic for research in teacher education. Thus, this paper aims to understand and explain how the construction of mathematical and didactical knowledge of teachers who teach mathematics at elementary school, in a formative process, on the different meanings of the equals sign, occurs. The research is qualitative-interpretative and data, documentary and audio records, come from a teacher education process developed with 6 teachers from a public school in São Paulo. Analyzes showed mobilization of mathematical and didactical knowledge, which was reorganized, developed and constructed, by the teachers
\end{abstract}

Submetido em: 20/09/2020 - Aceito em: 04/02/2021 - Publicado em: 28/05/2021

${ }^{1}$ Doutoranda em Didática da Matemática e Licenciada em Pedagogia pelo Centro Universitário Fundação Santo André. Professora da escola pública Municipal e Estadual de São Paulo, Brasil. E-mail lilian.barboza@ufabc.edu.br. ORCID: https://orcid.org/0000-0001-7323-595X

2 Doutor em Ensino de Ciências e Matemática pela Universidade Luterana do Brasil e Licenciado em Matemática pela Universidade Regional Integrada do Alto Uruguai e das Missões. Professor Adjunto na Universidade Federal do ABC, Brasil. E-mail: vinicius.pazuch@ufabc.edu.br. ORCID: https://orcid.org/0000$\underline{0001-6997-1110}$

${ }^{3}$ Doutor em Educação Matemática e Licenciado em Matemática pela Pontifícia Universidade Católica de São Paulo. Professor Associado na Universidade Federal do ABC, Brasil. E-mail: alessandro.ribeiro@ufabc.edu.br. ORCID: https://orcid.org/0000-0001-9647-0274 
DOI: 10.20396/zet.v29i00.8656716

through getting involved in this collective formative process of planning, developing and reflecting a mathematics lesson on the different meanings of equals sign. It is understood that such movements occurred through the use of professional learning tasks and the mediations and the teacher educator.

Keywords: Continuous education; Algebraic thinking; Equals sign; Mathematical and didactical knowledge.

\section{Introdução}

A formação continuada de professores que ensinam matemática nos anos iniciais pode ser discutida a partir de conexões e interlocuções entre os conhecimentos profissionais (Ball, Ben-Peretz \& Cohen, 2014; Ball \& Cohen, 1999; Silver et al., 2007; Smith, 2001) e as práticas letivas dos professores (Ponte et al., 2008; Serrazina, 2013). Discorre-se sobre a potencialidade de fundamentar este contexto de formação na mobilização e na construção do conhecimento dos professores que continuam a aprender no exercício de suas práticas profissionais (Opfer \& Pedder, 2011; Ponte \& Oliveira, 2002; Ponte \& Quaresma, 2016; Serrazina, 2013; Webster-Wright, 2009). As situações de práticas letivas podem ajudar nesse contexto reflexivo e de mobilização de conhecimentos matemáticos e didáticos.

Nesse sentido, o conhecimento do professor assume um papel fundamental em sua formação, pois "este está interrelacionado com o nível de confiança do professor quer relativamente à matemática e ao seu ensino, quer àquilo que considera que os seus alunos são capazes de aprender em Matemática" (Serrazina, 2013, p. 77). Logo, parece que é estabelecida uma relação positiva entre a confiança dos professores em sua prática letiva, que aumenta à medida que eles passam a construir novos conhecimentos específicos do conteúdo. Consequentemente, isso pode possibilitar um aprimoramento também no conhecimento sobre os estudantes e sobre os processos de ensino (Ball, Thames \& Phelps, 2008), o que, por sua vez, incide em saber mais matemática (Serrazina, 2013).

No âmbito da matemática, destaca-se o desenvolvimento do Pensamento Algébrico (PA) e a importância de trabalhar com ele desde os anos iniciais. Apontam-se aqui as potencialidades para os estudantes, ao se desenvolver o PA desde cedo, para posteriormente engajarem-se nos estudos de álgebra dos anos subsequentes do ensino fundamental (Blanton \& Kaput, 2008; Britt \& Irwin, 2011; Kieran et al., 2016). Este estudo, ao tomar como foco a relevância dessa abordagem, enfatiza o trabalho com os diferentes significados do sinal de igualdade (Kieran, 1981; Ponte, Branco \& Matos, 2009; Trivilin \& Ribeiro, 2015).

Não obstante, entende-se que é essencial intensificar a formação continuada de professores dos anos iniciais, de maneira a ampliar e (re)estruturar seus conhecimentos específicos para o ensino da matemática e seus conhecimentos sobre os estudantes e o currículo. Nesta perspectiva, pesquisas que investigam e apontam novos caminhos à formação continuada (Silver et al., 2007; Barboza, 2019; Barboza, Ribeiro \& Pazuch, 2019) também se constituem como ricas possibilidades, além de outros estudos que podem apresentar potencialidades à aprendizagem profissional (Ball \& Cohen, 1999; Smith, 2001). Ressaltam-se o uso de Tarefas de Aprendizagem profissional (TAP) e as discussões coletivas 
DOI: $10.20396 /$ zet.v29i00.8656716

que delas emergem, como meio possibilitador à aprendizagem do professor (Ribeiro \& Ponte, 2019).

Neste contexto, o objetivo deste artigo é compreender e explicar como ocorre, em um processo formativo sobre os diferentes significados do sinal de igualdade, a construção do conhecimento matemático e didático de professores que ensinam matemática nos anos iniciais.

Esta pesquisa ${ }^{4}$ fundamentou-se em uma abordagem qualitativa, de cunho interpretativo. Analisar-se-ão dados gerados a partir de 6 dos 14 encontros de um processo formativo proposto pela primeira autora deste artigo, do qual participaram 6 professoras dos anos iniciais de uma escola pública do município de São Paulo.

Apresenta-se a seguir a revisão de literatura. Posteriormente, o contexto da pesquisa e os aspectos metodológicos. Na sequência, discutem-se episódios de análise selecionados e, por fim, as conclusões e considerações finais.

\section{A prática letiva, os conhecimentos profissionais e a aprendizagem do professor}

O planejamento é uma ação inerente à prática letiva de professores que ensinam matemática (Serrazina, 2017) e uma vertente essencial ao ensino (O’Donnell \& Taylor, 2007). Logo, seu desenvolvimento exige ações pensadas, estruturadas e executadas cuidadosamente, possibilitando a ampliação do conhecimento do professor e possivelmente a melhoria do ensino. $\mathrm{O}$ ato de planejar uma aula de matemática com tarefas investigativas (Ponte, 2005) implica no conhecimento que o professor tem da matemática a ser trabalhada, na maneira como concebe a aprendizagem dos estudantes e as práticas em sala de aula.

Serrazina (2017) pondera que o ato de planejar não é uma tarefa simples, pois cabe ao professor considerar como os alunos pensam e como aprendem, ao envolver-se em uma proposta de aula. Planejar é traçar um caminho a trilhar, tendo em vista o trabalho com determinados conteúdos, estabelecendo quais objetivos se pretende alcançar, quais seriam os melhores caminhos para mobilizar pensamentos, hipóteses e estratégias do conteúdo a ser desenvolvido, ou seja, deve-se estabelecer aonde se quer chegar e quais tarefas podem subsidiar esta trajetória (Ponte \& Oliveira, 2002; Serrazina, 2017). Portanto, a ação de planejar é um movimento de aprendizagem e ensino do professor, uma vez que para tal ação, inerente à sua prática letiva, ele tenha que pensar e repensar seu percurso de ensino e seleção de propostas. Logo, o planejamento implica estabelecer possíveis relações entre o que se pensa e de que maneira isso se relaciona com os desafios reais da sala de aula (Ponte, 2005; Serrazina, 2017).

\footnotetext{
${ }^{4}$ A pesquisa é parte do projeto "Conhecimento matemático para o ensino de álgebra: uma abordagem baseada em perfis conceituais”, aprovado no CEP da UFABC, processo número CAAE 55590116.8.0000.5594.
} 
Nessa perspectiva, o ato de planejar uma aula individualmente e, sobretudo, coletivamente, pode ser considerado uma possibilidade em programas de formação (inicial e continuada) de professores, devido à ação propícia de partilhar conhecimentos sobre o ensino, à forma como os alunos podem desenvolver e registrar seus pensamentos matemáticos, servindo de alicerce contra as (in)certezas que envolvem a prática letiva (Serrazina, 2017). Refletir a partir do que se planejou, sobre como se desenvolveu a tarefa pensada e a aula planejada também é uma forma de aprendizagem profissional (Ball \& Cohen, 1999).

Assim, o ato de planejar implica em alguns desdobramentos, seja na escolha das tarefas para os estudantes (Ponte, 2005), seja na forma como elas serão desenvolvidas (Stein et al., 2008), ou ainda nos objetivos matemáticos que devem ser alcançados. Tais desdobramentos podem apresentar-se como uma das facetas necessárias ao professor, para a mobilização dos conhecimentos matemáticos para o ensino (Ball, Thames \& Phelps, 2008).

Assumimos em nosso estudo, que os conhecimentos matemáticos e didáticos (Ball, Thames \& Phelps, 2008) são importantes componentes da aprendizagem profissional do professor (Ball \& Cohen, 1999). Assim, iremos considerar que os conhecimentos profissionais alimentam e conectam-se ao ato de planejar, desenvolver e refletir sobre a aula torna fundamental a mobilização desses conhecimentos e consequência promoção de aprendizagem profissional aos professores. Assim, pode-se questionar: sendo a prática reflexiva um componente essencial para o trabalho docente, quais conhecimentos são essenciais à formação desse profissional? Quais relações podem ser estabelecidas entre os conhecimentos profissionais dos professores que ensinam matemática nos anos iniciais e sua prática letiva?

De acordo com Shulman (1986, 1987), só se pode ensinar aquilo que se sabe, e ensinar ao outro o que se sabe é a confirmação de ter compreendido o assunto e transformado o próprio conhecimento em possibilidade de ensino e aprendizagem de outros. A partir dos trabalhos de Shulman, posteriormente direcionados à área da matemática, pelos estudos de Ball, Thames e Phelps (2008), temos a constituição da noção de Mathematical Knowledge for Teaching (MKT).

O modelo teórico proposto por Ball, Thames e Phelps (2008) parte do pressuposto da necessidade de identificar e compreender quais são os conhecimentos de que os professores precisam para atuar na prática letiva e de que forma é possível mobilizá-los. Logo, os autores propõem uma base de conhecimentos matemáticos e didáticos a fim de alicerçar a realização das tarefas correlatas ao ensino.

Com base nos autores anteriormente citados, o Conhecimento Específico do Conteúdo, refere-se ao conteúdo matemático a ser ensinado e subdivide-se em: conhecimentos usados além dos conteúdos de ensino, denominados Conhecimento Comum do Conteúdo $\left(\mathrm{CCK}^{5}\right)$; conhecimentos matemáticos que possibilitam ao professor saber como

\footnotetext{
${ }^{5}$ Optou-se por manter as siglas em inglês, devido à popularização destas em trabalhos nacionais e internacionais sobre o tema.
} 
se constroem os tópicos matemáticos ao longo de todo o currículo escolar, chamados de Conhecimento do Conteúdo no Horizonte (HCK); e conhecimento voltado apenas ao ensino da matemática, ou seja, aquele tipo de conhecimento que se considera indispensável para exercer a função de professor, denominado de Conhecimento Especializado do Conteúdo (SCK).

Em complemento, o Conhecimento Pedagógico do Conteúdo, referindo-se ao modo como o conteúdo pode ser ensinado, é subdividido também em outros três conhecimentos: o conhecimento sobre o que será ensinado, de maneira tal que possibilite ao professor antecipar os possíveis erros a serem cometidos pelos estudantes, denominado de Conhecimento do Conteúdo e dos Estudantes (KCS); o conhecimento que possibilita ao professor saber sobre o ensino e sobre a matemática, designado de Conhecimento do Conteúdo e do Ensino (KCT); e o conhecimento dos conteúdos específicos que compõem o currículo que será estudado, intitulado de Conhecimento do Conteúdo e do Currículo (KCC).

Os autores Russ, Sherin e Sherin (2016) discutiram pesquisas sobre a aprendizagem profissional, objetivando responder à questão "Como os professores aprendem a ensinar?". Estes autores abordam pesquisas nesta temática com três perspectivas: processo-produto, cognitiva e sociocultural. Ressalta-se aqui a perspectiva cognitiva, que pode trazer evidências de como as categorias de conhecimentos profissionais são constituídas e através de quais processos se desenvolvem.

Trabalhos como o de Ma (1999) destacam que um processo central da aprendizagem do professor é a formação de novas estruturas de conhecimento, combinando várias de suas esferas e potencialmente algum novo conhecimento, seja individualmente ou em espaços coletivos.

Sendo os conhecimentos matemáticos e_didáticos essenciais para ensinar, tendo em vista os argumentos expostos anteriormente, a seguir apresenta-se a importância do desenvolvimento do PA desde os anos iniciais e, especificamente, em relação ao trabalho com os diferentes significados do sinal de igualdade.

O desenvolvimento do Pensamento Algébrico e os diferentes significados do sinal de igualdade

Pesquisas indicam as possibilidades e a necessidade de trabalhar o desenvolvimento do PA desde os anos iniciais (Blanton \& Kaput, 2005, 2008; Britt \& Irwin, 2011; Kieran et al., 2016). Esse fato pode contribuir para a transição dos estudantes para o estudo mais formal da álgebra nos anos finais do ensino fundamental.

Blanton e Kaput (2005) salientam que o PA, em estudantes dos anos iniciais, é

[...] um processo no qual os alunos generalizam ideias matemáticas de um conjunto particular de exemplos, estabelecem generalizações por meio do discurso de argumentação, e expressam-nas, cada vez mais, em caminhos formais e apropriados à sua idade. (Blanton \& Kaput, 2005, p. 413) 
DOI: $10.20396 /$ zet.v29i00.8656716

Britt e Irwin (2011), ao referenciar algumas das habilidades dos alunos no que se refere ao PA, remetem ao conhecimento matemático do professor e à formação necessária desse profissional para o trabalho com o PA nos anos iniciais. Os autores afirmam, ainda, que os professores precisam desenvolver suas próprias habilidades de PA, para posteriormente ensinar. Em consonância, Ponte e Branco (2013) argumentam que, antes de promover o PA em salas de aula, os professores precisam desenvolver o domínio pessoal do que significa pensar algebricamente.

Tomando-se a compreensão dos diferentes significados do sinal de igualdade como uma das temáticas a ser desenvolvida no campo do PA (Ponte, Branco \& Matos, 2009), considera-se, a partir do estudo desses autores, a importância que assume o conceito de igualdade na Matemática, pois o sinal de igualdade tem um papel importante na compreensão do conceito de equivalência. Os autores ressaltam: "a igualdade ou equivalência matemática é sempre relativa apenas a uma certa propriedade" (Ponte, Branco \& Matos, 2009, p. 19). É importante lembrar que, na Matemática, a relação de igualdade é uma relação de equivalência que respeita três propriedades, a saber: a simétrica $(4+2=6$ ou $6=2+4$ ou $3+3=1+5)$; a reflexiva $(5=5)$; e a transitiva $(2+5+3=7+2+1=8+2=10)$ (Ponte, Branco \& Matos, 2009).

No trabalho de Kieran (1981) são elencados três significados diferentes para o sinal de igualdade: operacional, equivalência e relacional. O significado operacional é o mais trabalhado nos anos iniciais e, muitas vezes, o único. É o significado operacional que confere ao aluno a ideia de que, após este símbolo "=", deve-se sempre colocar o resultado de uma operação e, geralmente, só é aceita como verdadeira uma única quantidade (p. e. 5+13=18). Nestas circunstâncias, os estudantes ficam limitados a compreender o sinal de igualdade como "um sinal de fazer algo (Behr, Erlwanger \& Nichols, 1980); uma ação indicada que significa: dá ou faz (Stacey \& Macgregor, 1997); um operador que transforma, por exemplo, $3+4$ em 7" (Trivilin \& Ribeiro, 2015).

Já o segundo significado do sinal de igualdade, o de equivalência, é aquele que permite estabelecer muitas formas de representar o 20 - por exemplo, por meio de igualdades numéricas, como $20=12+8 ; 17+3=20 ; 20=18+2-$, assim como indica possibilidades de trabalhar expressões como $17+3=18+2$, expressando uma relação de equilíbrio, de equivalência entre os termos "antes" e "depois" do sinal. Trabalhar este significado nos anos iniciais é muito importante para possibilitar a compreensão de conceitos algébricos dos anos subsequentes, como o conceito de equação, o qual é amplamente estudado nos anos finais do ensino fundamental (Ribeiro \& Cury, 2015).

Por fim, o último significado do sinal de igualdade é o relacional, pelo qual se estabelecem relações entre expressões, e que implica na compreensão e no uso das propriedades das operações (adição e multiplicação). Nesse caso, o sinal de igualdade é fundamental para que se compreenda, por exemplo, a expressão $10+12+15=10+10+17$.

Passa-se, a seguir, a apresentar as TAP como um dos principais instrumentos de produção de dados desta pesquisa. 
DOI: $10.20396 /$ zet.v29i00.8656716

\section{As Tarefas de Aprendizagem Profissional e suas potencialidades}

Salienta-se que os professores precisam de oportunidades para aprender: (i) o assunto que ensinam (significados e conexões na vida cotidiana, e não apenas procedimentos e informações); (ii) o conhecimento dos estudantes: como pensam, como aprendem, o porquê de cometerem equívocos, como ouvi-los atentamente e como ajudá-los a avançar; (iii) a necessidade de desenvolver a capacidade de superar os desvios sociais e étnicos, e ter sensibilidade ao ajuste e à adaptação necessários para atingir cada aluno, buscando estratégias para que todos aprendam (Ball \& Cohen, 1999).

Sendo assim, as TAP são compostas de situações a serem exploradas, possibilitando a formulação de conjecturas matemáticas, sua validação, reformulação e a mobilização de conhecimentos necessários à prática letiva. Esses podem estar voltados às antecipações dos pensamentos dos estudantes ou ligados à análise de protocolos reais e fictícios que eles podem produzir (Barboza $\left.{ }_{2} 2019\right)$.

Em consonância às discussões anteriores, Silver et al. (2007) argumentam ainda que as TAP têm potencialidade para oportunizar aprendizagem para professores, ao tratar uma situação, a construção de um conceito matemático e a resolução de tarefa como problemática. Esses autores esperam também que a interação entre os professores e o formador, no uso de TAP, possa ser um fator importante à promoção de oportunidades de aprendizagem, baseadas na prática.

Assim, as TAP parecem favorecer a eminência de oportunidades de aprendizagem profissional (Ball \& Cohen, 1999; Ribeiro \& Ponte, 2019; Webster-Wright, 2009), uma vez que nelas estão contidas, normalmente, "amostras autênticas de prática" (Ball \& Cohen, 1999; Silver et al., 2007; Smith, 2001), ou seja, materiais extraídos em salas de aulas reais. Com isso, entende-se que são abertos espaços para críticas, questionamentos e investigações, possibilitando a (re)estruturação de conhecimentos para o ensino e sobre os estudantes e a mobilização de conhecimentos matemáticos. As TAP oportunizam aos professores desenvolver conhecimento central ao ensino, uma vez que eles se engajam em tarefas e atividades que são o cerne de seu trabalho diário (Smith, 2001).

Logo, uma maneira para projetar uma TAP é considerar o ciclo do trabalho dos professores e a natureza das atividades que os envolvem. Em outras palavras, considera-se o ato de planejar o que se quer ensinar, quais tarefas poderiam propiciar e elucidar o conhecimento matemático a ser construído. Em consequência disso, ocorrem a execução do planejamento em sala de aula e, finalmente, uma reflexão posterior sobre o que será preciso (re)formular para a efetiva aprendizagem do conhecimento pelos estudantes (Ball, BenPeretz \& Cohen, 2014; Smith, 2001).

As TAP são potenciais ferramentas para a aprendizagem profissional, por estarem alicerçadas em questionamentos centrados na prática; oportunizarem abertura de perspectivas comparativas sobre a prática; contribuírem com questionamentos pessoais e coletivos; e favorecerem a (re)significação/transformação das práticas (Ball \& Cohen, 1999; Smith, 2001; Silver et al., 2007). Sendo assim, compreende-se que as TAP são instrumentos ou materiais 
planejados pelo formador, de maneira a possibilitar discussões e reflexões sobre os conhecimentos matemáticos e didáticos do professor.

Tendo explorado a literatura relacionada ao nosso problema de pesquisa, bem como, situando os aspectos teóricos de nosso estudo, na próxima seção estruturaram-se o contexto investigativo e os procedimentos metodológicos.

\section{Contexto da investigação e procedimentos metodológicos}

Nesta seção, apresentar-se-ão os contextos nos quais a pesquisa foi realizada, os procedimentos metodológicos adotados e a forma pela qual se deu a recolha e a análise dos dados.

O estudo deu-se no contexto de um processo formativo com 6 professoras dos anos iniciais em exercício (Adionísia, Celeste, Kátia, Luciana, Márcia e Valdete), em uma escola pública municipal, em São Paulo, com a participação da primeira autora. Os dados foram produzidos em 14 sessões de trabalho presenciais, no período de agosto a outubro de 2018.

Em linhas gerais, nos primeiros encontros do processo formativo, o objetivo central foi mapear os conhecimentos matemáticos prévios das professoras sobre os diferentes significados do sinal de igualdade e discutir elementos teóricos e metodológicos para a instrumentalização das aulas das próprias professoras. Por outro lado, em outros encontros, trabalhou-se com TAP no intuito de mobilizar conhecimentos matemáticos e pedagógicos. Considerando o foco deste artigo, apresenta-se, no Quadro 01, uma síntese dos encontros 9, 10, 11, 12, 13 e 14, nos quais se incluem a TAP de planejamento coletivo de uma aula e seu desenvolvimento, e outra TAP que contemplava possibilidades de reflexões sobre a aula desenvolvida.

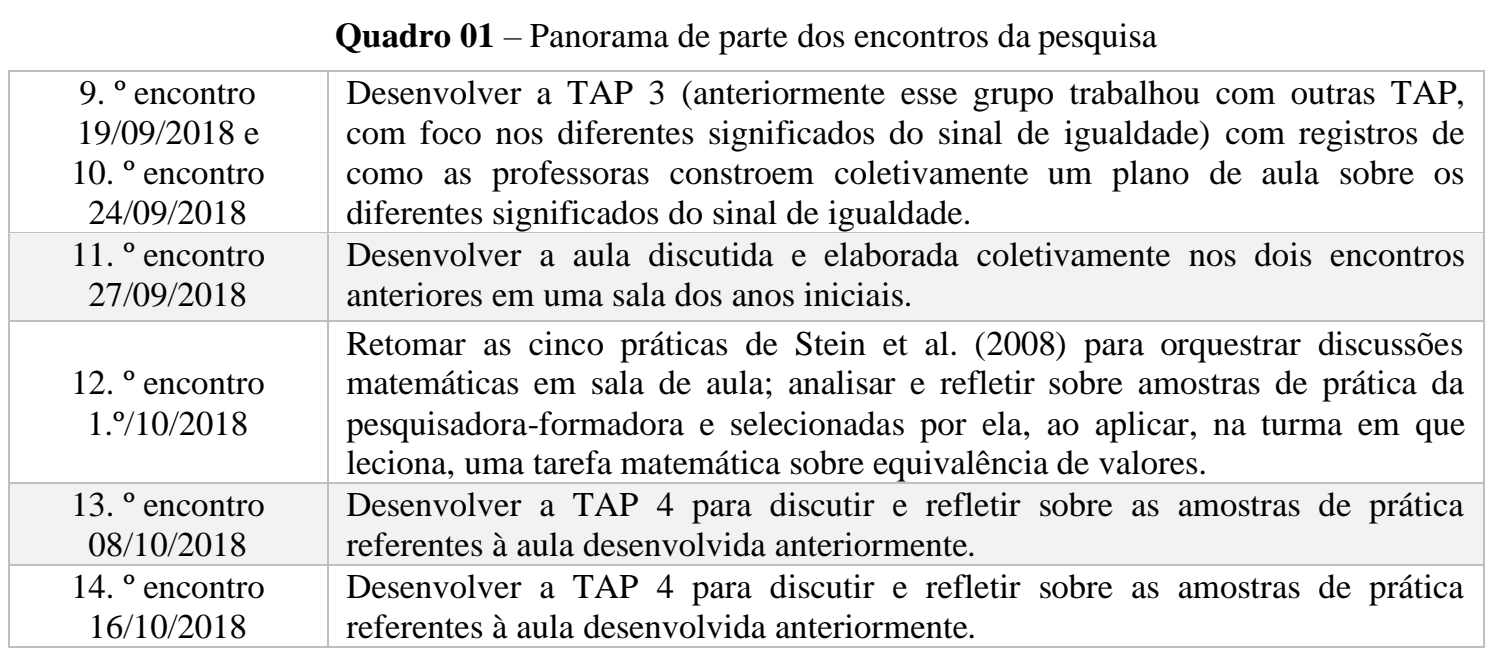

Fonte: (Barboza, 2019)

No nono encontro, as professoras dividiram-se em dois grupos, e estabeleceu-se uma dinâmica com dois momentos: no primeiro, cada grupo lia, refletia, discutia, registrava suas conjecturas e discutia sobre as tarefas que poderiam ser usadas na aula para trabalhar o significado de equivalência do sinal de igualdade. Concomitantemente, havia intervenções 
pontuais da pesquisadora-formadora $(\mathrm{PF})$, que circulava entre os dois grupos. No segundo momento, abria-se a plenária para que cada questão, resolução e discussão feita nos grupos fosse compartilhada entre os dois grupos. A partir do décimo encontro, por sugestão das professoras, as seis passaram a trabalhar de forma conjunta, em um único grupo.

Do ponto de vista metodológico, esta pesquisa se insere em uma abordagem qualitativo-interpretativa (D'Ambrosio, 2004; Esteban, 2010). Os dados foram recolhidos por meio de dois instrumentos e procedimentos, a saber: (I) as TAP, com enfoques no planejamento, no desenvolvimento e na reflexão de uma aula, a fim de possibilitar uma variedade de discussões e abordagens relativas ao conhecimento específico, ao conhecimento dos estudantes e dos processos de ensino e ao conhecimento do currículo; (II) as gravações em áudio e vídeo, realizadas ao longo dos encontros, de modo a obter um maior detalhamento do trabalho das professoras no decorrer do desenvolvimento das TAP.

As TAP se caracterizaram como o principal instrumento para coleta dos dados e foram estruturadas pela pesquisadora-formadora, tomando-se por base: (i) o que os professores precisam saber sobre matemática para o ensino dos diferentes significados do sinal de igualdade; (ii) quais práticas letivas irão oportunizar aos alunos e às alunas a interação e a construção de conhecimentos; (iii) quais tipos de tarefas e abordagens são potenciais ao ensino do sinal de igualdade.

Tais fundamentos se ancoram nos domínios MKT, a saber: reconhecer os possíveis erros e equívocos cometidos pelos estudantes e dimensionar a sua natureza (SCK); planejar o ensino, pensar sobre a disposição dos estudantes, escolher e elaborar as tarefas e antecipar as respostas dos estudantes (KCS); compreender os desdobramentos do ensino dos diferentes significados do sinal de igualdade desde os anos iniciais e seu impacto nos anos escolares subsequentes (HCK e CCK); compreender as diferenças dos tipos de tarefas e as possíveis intervenções para entender mais profundamente o conteúdo trabalhado (KCT).

Ressalta-se que, por serem as TAP tarefas investigativas - na perspectiva de Ponte, Brocardo e Oliveira (2003) (por apresentarem em sua estrutura e desenvolvimento uma introdução, seu desenvolvimento nas discussões em pequenos grupos, o compartilhamento no coletivo e sua sistematização) com amostras da prática letiva e tarefas matemáticas dos estudantes, seus protocolos de resolução e estratégias podem criar oportunidades enriquecedoras à capacidade dos professores para compreender e tomar decisões em relação às suas práticas letivas. São as TAP uma fonte instrumentalizadora aos professores, de maneira que eles, ao planejar e desenvolver ou, em sala de aula, promover uma tarefa matemática, possam apoiar a aprendizagem dos estudantes, criando ambientes que promovam a comunicação entre os pares, o levantamento de hipóteses, os questionamentos e a troca de diferentes resoluções.

Para a construção da unidade de análise deste artigo, "Mobilizando e construindo conhecimentos ao planejar coletivamente: da antecipação dos passos da ação à posterior reflexão". Esta unidade de análise contempla os processos coletivos envolvidos no planejamento, na ação e na reflexão sobre os conhecimentos do professor constituídos no 
âmbito da formação continuada. Consideraram-se as transcrições dos encontros 9, 10, 11, 13 e 14, bem como as produções escritas produzidas pelo grupo de professoras, ao desenvolverem as TAP 3 e TAP 4. Em seguida, agruparam-se essas informações, criando-se assim um inventário que foi separado por encontro e por instrumento de coleta. Tal procedimento foi adotado de tal modo que, reunindo-se as informações dessa maneira, elas poderiam ser comparadas e analisadas.

A partir do inventário - seleção de todas as informações advindas dos instrumentos usados nesta pesquisa -, organizou-se um episódio para análise, voltado ao planejamento, ao desenvolvimento - e à reflexão sobre ela - de uma aula sobre o significado equivalente do sinal de igualdade. $\mathrm{O}$ episódio será discutido no item a subsequente, em que se apresentam 17 excertos, entre diálogos (11) e figuras (6).

O episódio selecionado é fruto dos dados gerados no trabalho desenvolvido: com a TAP 3, cujo objetivo foi entender como as professoras constroem coletivamente um plano de aula sobre os diferentes significados do sinal de igualdade, selecionando e antecipando as resoluções de uma tarefa e seus objetivos; e com a TAP 4, a qual teve como objetivo refletir sobre as amostras de prática - fruto das narrativas, transcrição de áudios, trechos transcritos da aula desenvolvida e gravada em vídeo e protocolos dos estudantes - previamente selecionadas pela $\mathbf{P F}$, da aula desenvolvida pela professora Celeste, em sua turma de $5 .^{\circ}$ ano, e sua relação com o planejamento coletivo feito na TAP 3.

Como forma de codificação das informações utilizadas nas análises, adotou-se o seguinte procedimento: após a descrição da informação, aparece o nome real das participantes, seguido de uma letra e um número, referentes ao instrumento (T3 ou T4) para TAP 3 ou TAP 4, respectivamente; (D), para as transcrições nos pequenos grupos; (Pn), para as transcrições das plenárias, sendo n o número do encontro; por fim, a data do encontro em que a informação foi obtida. Por exemplo, para identificar uma informação fornecida por Luciana, no nono encontro, em 19/09/2018, durante as discussões em grupo, utilizou-se: (Luciana, D9, 19/09/2018). Para os estudantes, manteve-se o mesmo procedimento colocando-se o termo "estudantes", seguido da letra inicia "E”(n), sendo n a indicação da dupla ou trio; para a transcrições das plenárias a letra $\mathrm{P}$, seguida do número do encontro que as professoras assistiram e analisaram os trechos audiogravados; finalizando com a data em que o encontro das professoras ocorreu. Por exemplo, para identificar uma informação fornecida por um estudante da dupla 1, outro da dupla 2 e outro da dupla 3, para análise das professoras no $11^{\circ}$ encontro, em 27/09/2018, utilizou-se: (Estudantes (1), (2) e (3), P11, 27/09/2018).

Na próxima seção_discutimos os resultados de nosso estudo, buscando relacionar nossas análises e interpretações à excertos de dados advindos de nossa pesquisa de campo. 


\section{"Planejando coletivamente - da antecipação dos passos da ação à posterior reflexão": análise dos dados}

Para as análises foram selecionados excertos que apontam para a compreensão de como se deram a mobilização e a construção de conhecimentos matemáticos e pedagógicos das seis professoras que colaboraram com esta pesquisa e suas discussões, seus registros e reflexões, ao envolver-se nas TAP 3 e 4.

Para iniciar o trabalho com a TAP 3, a PF fez a leitura coletiva, e cada trio acompanhou com sua cópia (Figura 1).

Os dois grupos iniciaram pela análise das tarefas matemáticas - o que elas traziam de desafios e propostas, de que maneira poderiam trabalhá-las em sala de aula, o que antecipar e de que maneira trabalhar com os estudantes. Logo, pode-se conjecturar que as professoras estavam a mobilizar e com oportunidades de construir os seus conhecimentos sobre o CK e o PCK, especificamente no que se refere ao SCK, ao KCS e ao KCT. O grupo das professoras Celeste (C), Luciana (L) e Kátia (K) escolheu a tarefa "O jogo de boliche” (Figura 2).

Durante as discussões promovidas pelo trio de professoras Celeste $(\mathrm{C})$, Kátia $(\mathrm{K})$ e Luciana (L), no primeiro dia de desenvolvimento da TAP 3 (Figuras 1, 2), momento de escolha da tarefa matemática, inicialmente anteciparam as possíveis resoluções para a tarefa escolhida, as dificuldades dos estudantes ao realizá-la e até indicaram algumas razões para potenciais equívocos e possíveis desdobramentos:

[1] K - Olha essa questão [referindo-se à questão 4 - Figura 2], eles que vão determinar. Cada um pode ter suas possibilidades, cada um vai fazendo sua hipótese.

[2] C - Sim, cada um vai distribuir como achar melhor, desde que ele atinja 20 no total.

[3] K - Sim, muitas possibilidades.

[4] PF - Será que eles estão sempre habituados que pode ter mais de um resultado certo?

[5] K - Não.

[6] C - Não, porque eles sabem que eles podem ter várias estratégias para atingir uma resposta, um só resultado. Mas vários resultados certos...

[7] $\mathrm{PF}$ - E vocês acham que isso é um desafio a mais?

[8] C - Eu acho que é um desafio a mais, sim.

[9] K - Fora que eles ficam preocupados se o que ele colocou é certo e está igual ao do colega.

[10] L-É mesmo. E ficam "será que eu errei?"

[11] C - Sim, porque tem que ser tanto e igual ao do outro.

[12] $\mathrm{K}-$ E isso é um bom desafio.

(Celeste, Kátia, Luciana, Pesquisadora/Formadora, D9, 19/09/2018). 
DOI: 10.20396/zet.v29i00.8656716

De acordo com nossas discussões e leituras nos encontros anteriores, hoje a proposta é elaborarmos uma tarefa para ser aplicada na turma do $5^{\circ}$ ano $\mathrm{A}$, da professora Celeste. A proposta é seguirmos os passos do planejamento de aula, discutidos por nós no encontro de 28/08/2018, apoiadas em Serrazina (2017).

Vamos primeiro retomar os passos sugeridos pela autora. Eles estabelecem que devemos definir o(s) objetivo(s) que queremos trabalhar; escolher a tarefa ou elaborá-la/adaptála e estabelecer o que pode ser antecipado em relação às possíveis estratégias de resolução dos estudantes; fazer as antecipações das possiveis dificuldades que os estudantes podem apresentar ao fazer a tarefa; antecipar as formas alternativas de resolução da tarefa e possíveis conexões entre elas; antever a possibilidade do uso de materiais manipulativos ou de recursos para o desenvolvimento da tarefa; antecipar alguns questionamentos e questões-chaves que relacionem conteúdos anteriormente trabalhados; pensar em como propor a tarefa de maneira a orquestrar discussões matemáticas. Conforme exposto na figura abaixo, temos alguns passos a seguir que, não necessariamente, precisam ser realizados na ordem apresentada:

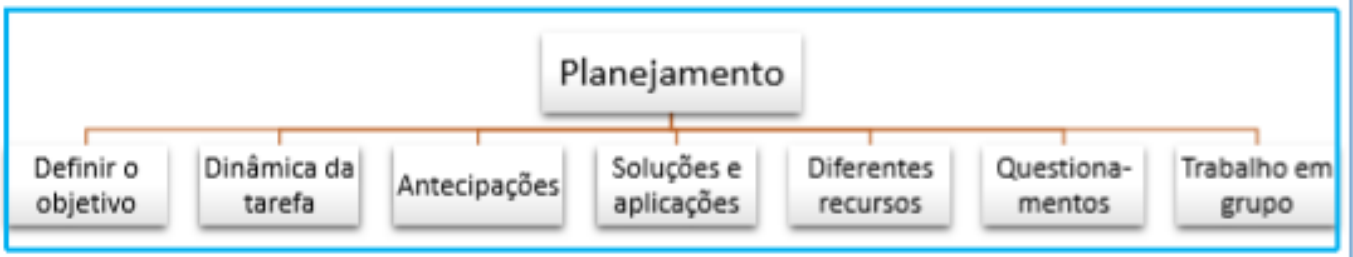

Em anexo, vocês têm algumas sugestões de tarefas, mas podem elaborar novas ou fazer adaptações nas que sugiro.

Algumas questões gerais que podem nortear as escolhas que irão fazer: (i) Quais conhecimentos prévios a turma precisa mobilizar para responder à tarefa?; (ii) Quais conteúdos matemáticos estão envolvidos na tarefa?; (iii) Como desenvolver esta tarefa em sala de aula?; (iv) Caso quiséssemos utilizar o sinal de igual com significado de operador, que perguntas poderíamos propor?; (v) Caso quiséssemos utilizar o sinal de igual com significado de equivalência, que perguntas ou modificaçōes na escrita da tarefa poderiam ser feitas?; (vi) Que outras perguntas poderiam ser feitas?

Figura 1 - TAP 3: Planejar o percurso

Fonte: Barboza (2019) 
DOI: 10.20396/zet.v29i00.8656716

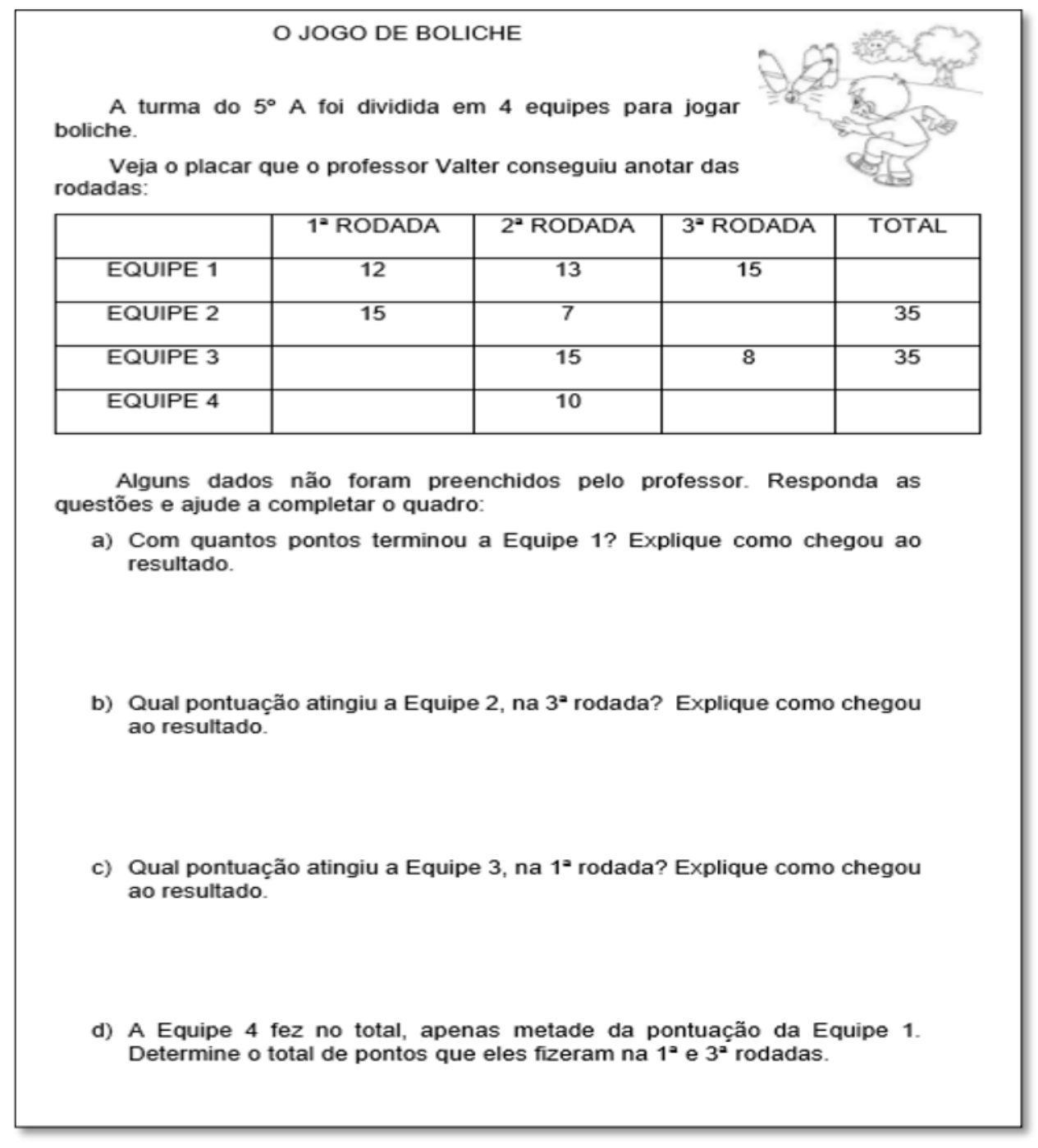

Figura 2 - Tarefa matemática escolhida para o planejamento da aula Fonte: (Barboza, 2019).

No decorrer das discussões, a PF introduziu uma questão, de maneira a propor reflexões sobre o significado de equivalência do sinal de igualdade:

[13] $\mathrm{PF}-E$ vocês acham que, nesta questão ou em alguma outra, eles conseguiriam olhar e estabelecer relações de equivalência?

[14] K- Sim.

[15] PF - E por quê? Fala mais.

[16] K - Por que eles vão perceber que...

[17] C - Você pode adicionar algarismos diferentes e obter o mesmo resultado.

[18] K - Porque não está determinado, então pode ser diferente.

(Celeste, Kátia, Pesquisadora/Formadora, D9, 19/09/2018).

De acordo com os excertos [13] e [14], por exemplo, é possível conjecturar que elas compreendiam o significado de equivalência do sinal de igualdade e estavam a desenvolver suas próprias habilidades de pensar algebricamente (Britt \& Irwin, 2011; Ponte \& Branco, 2013). Ainda, é possível conjecturar que estavam a mobilizar e construir os seus 
conhecimentos relativos ao SCK [13] e [14], como dito anteriormente, no que se refere à ampliação de seus conhecimentos sobre os significados do sinal de igualdade. Além disso, conhecimentos também relativos ao KCS [1], [2] e [3], e [7], [8] e [9], sobre possibilidade de pensar sobre possíveis erros e equívocos cometidos por alunos. Por fim, em [1], [4] e [6] pode se observar que as professoras tiveram oportunidades de compreender as diferenças dos tipos de tarefas e as possíveis intervenções possibilitadoras para entender de modo mais aprofundado o conteúdo (KCT) (Ball, Thames \& Phelps, 2008).

Diante das discussões, a PF introduziu outra questão, de maneira a propor novas reflexões acerca do significado de equivalência do sinal de igualdade e um olhar atento às possibilidades de relações que se poderiam estabelecer entre os dados que faltam na tabela (Figura 2).

[19] PF - Olhem a equipe 2 e a equipe 3, o que elas têm em comum?

[20] C-O mesmo resultado.

[21] PF - E nas rodadas, vejam se têm alguma relação.

[22] C - Hum, as duas têm 15.

[23] PF - E na outra rodada, um tem 7 e o outro tem 8. Será que observar isso pode ser uma forma de olhar para qual será a relação entre esses dois espaços a completar?

[24] L - Eu acho que não, acho que eles vão só calcular.

[25] C - Acho difícil olharem isso. Porque acho que vão somar as parcelas, que é a prática deles e depois vão tirar a parcela menor e tirar da maior para achar o valor desconhecido.

[26] L - Mas talvez depois do cálculo eles possam observar a tabela.

[27] C - Ah, sim, e dizer "olha o que aconteceu aqui".

(Celeste, Luciana, Pesquisadora/Formadora, D9, 19/09/2018).

Este mesmo trio ainda apontou as razões que justificavam a escolha da tarefa matemática e expôs às demais professoras algumas conjecturas matemáticas:

[28] K - Nós optamos pela do boliche, porque aqui eles vão também ter que encontrar os resultados. Verificar entre uma equipe e outra. Vão fazer operações inversas para descobrir os resultados. Já com a equipe 4, a gente viu que vai trazer bastante desafio para eles também, porque aqui, cada um pode colocar um resultado. E eles vão ver o quê??! Que na equivalência tem várias possibilidades para chegar ao mesmo resultado. Que não necessariamente o que ele colocou vai ser o que o colega colocou também. Porque eles acham que sempre tem o mesmo resultado. Que parcelas diferentes dão o mesmo resultado.

[29] L - E depois a gente verificou, com a ajuda da Lilian ${ }^{6}$, que tem uma relação aqui entre a equipe 2 e 3, que repete uma das pontuações. E dá para trabalhar a equivalência. Tirar a visão de cálculo linear. Porque na verdade a gente tem essa visão de cálculo linear. Aqui a gente mesmo

\footnotetext{
${ }^{6}$ Lilian é a primeira autora do artigo, que atuou como pesquisadora e formadora nos encontros formativos da pesquisa.
} 
DOI: $10.20396 /$ zet.v29i00.8656716

começou com esta visão, porque aí você faz toda essa dinâmica de comparar, relacionar. Porque a gente não tem este costume.

(Kátia E Luciana, P10, 24/09/2018).

Tais discussões parecem revelar que, à medida que avançavam os encontros e o desenvolvimento das TAP, as professoras se apropriavam dos conhecimentos acerca dos diferentes significados do sinal de igualdade (Barboza, Ribeiro \& Pazuch, 2019; Trivilin \& Ribeiro, 2015) e os ampliavam. Elas indicavam diferentes possibilidades de resolução, usando termos matemáticos convencionais, como "equivalência", e ainda comentavam que os estudantes poderiam cometer determinados equívocos, pois, muitas vezes, reforça-se na escola apenas um tipo de significado do sinal de igualdade, ou apenas uma forma linear de operação: a que ressalta somente o significado operacional do sinal de igualdade (Ponte, Branco \& Matos, 2009).

Diante da concordância sobre o uso da tarefa matemática (Figura 2) que seria desenvolvida na sala da professora (C), as seis professoras estabeleceram quais objetivos podiam ser desenvolvidos na aula em que a tarefa seria utilizada, apoiadas na unidade temática "álgebra", da Base Nacional Comum Curricular (Brasil, 2017) e no eixo “álgebra”, do Currículo da Cidade de São Paulo (São Paulo [município], 2017):

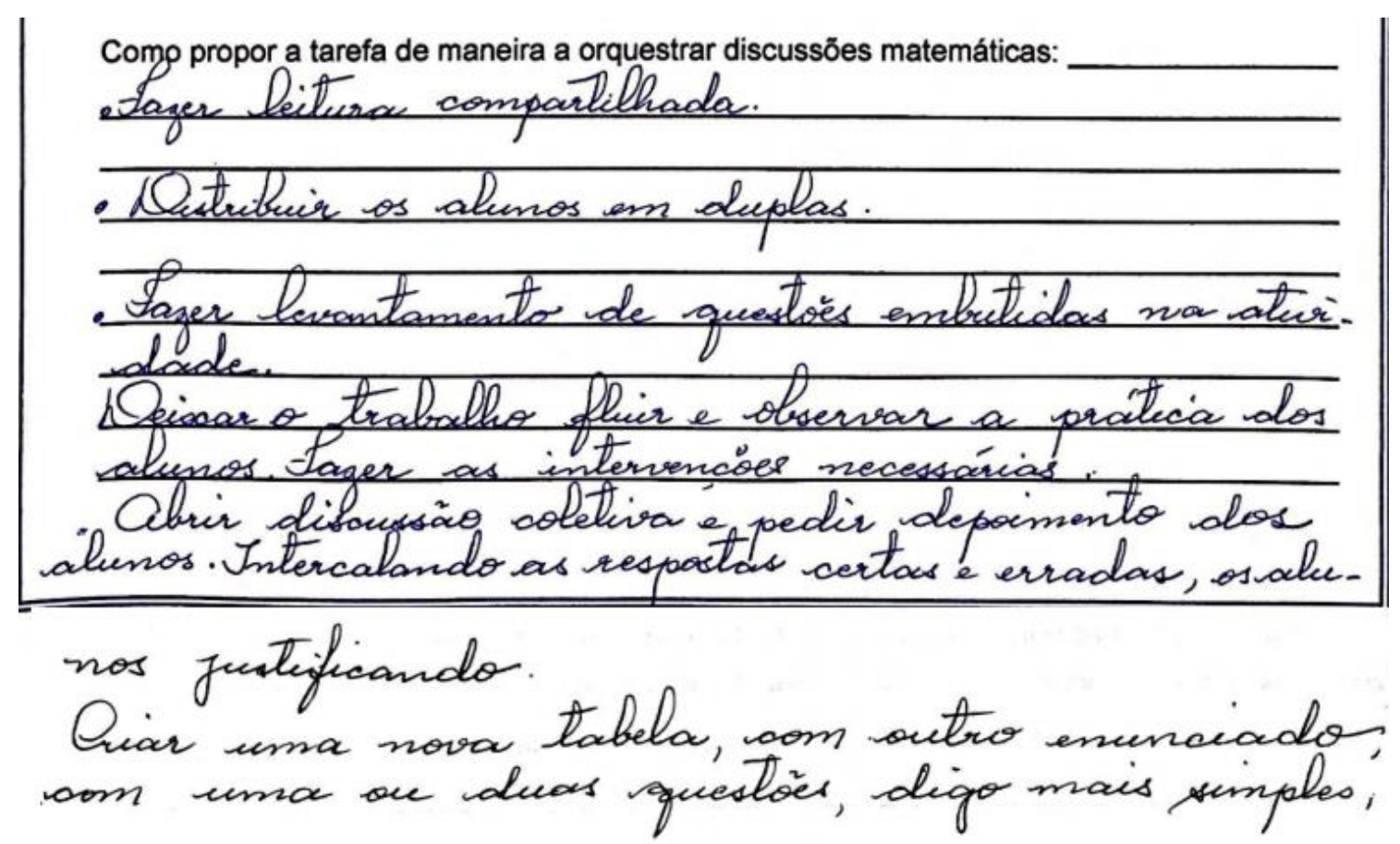

Figura 3: Protocolo apresentado - como propor a tarefa matemática TAP 3

Fonte: Adionísia, Celeste, Kátia, Luciana, Márcia e Valdete (TAP 3, 24/09/2018)

Posteriormente, as professoras anteciparam as possíveis dificuldades que os estudantes poderiam ter ao realizarem a tarefa matemática escolhida (Figura 4): 


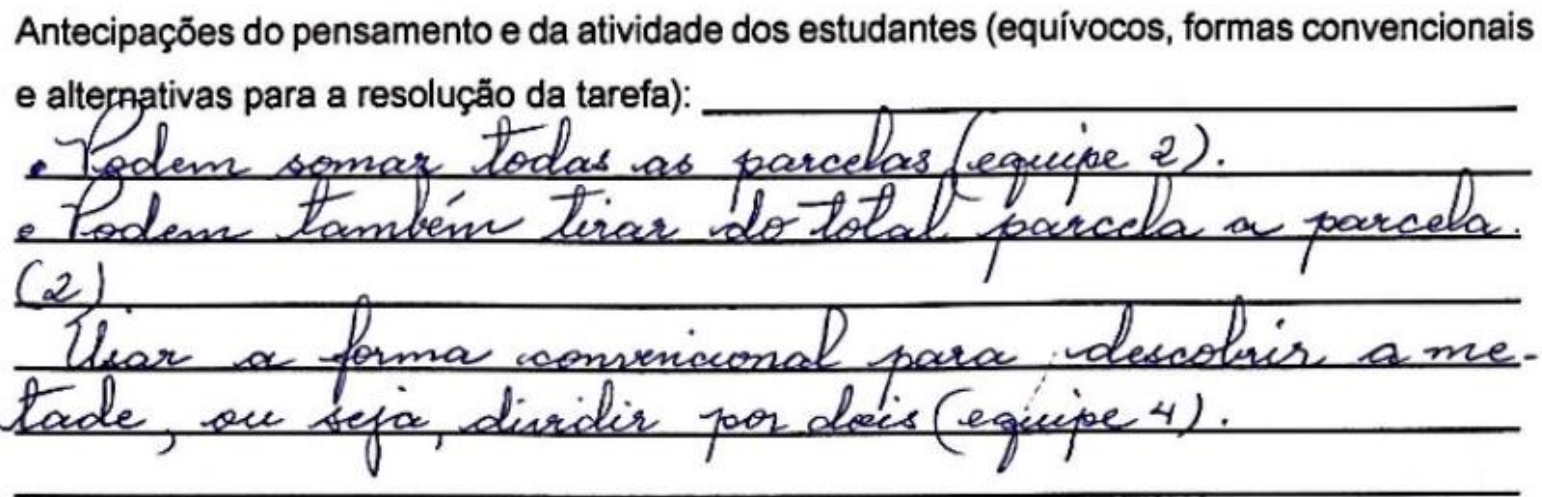

Figura 4: Protocolo apresentado - antecipação do pensamento dos estudantes- TAP 3 Fonte: Adionísia, Celeste, Kátia, Luciana, Márcia e Valdete (TAP 3, 24/09/2018)

As professoras estavam criando contextos para a sala de aula (Figura 3), de maneira a possibilitar interações significativas em torno do conteúdo a ser trabalhado, de modo que os alunos pudessem avançar nessa aprendizagem (Russ, Sherin \& Sherin, 2016). Isso pode evidenciar como os domínios de conhecimentos profissionais são constituídos e por meio de quais processos se desenvolvem. Também se pode conjecturar que nesse momento as professoras, a partir da TAP e das discussões, estavam mobilizando o KCS (Figura 3 e 4), [19], [20], [22] e, sobretudo, o KCC [28, 29]. Infere-se isso, pois as professoras demonstravam compreensão dos desdobramentos do ensino de diferentes significados do sinal de igualdade desde os anos iniciais e de seu impacto nos anos escolares subsequentes, como parte do conhecimento do conteúdo e do currículo.

Durante a TAP 4, quando as professoras assistiram a dois episódios, selecionados previamente, os estudantes falavam sobre as diferentes possibilidades para responder à questão D da tarefa (Figura 2). Pode-se observar que, nas transcrições dos diálogos 1, 2 e 4, na TAP 3, de planejamento, as professoras declararam que seria "um desafio a mais" o fato de os estudantes terem diferentes possibilidades para chegar ao resultado. Logo, elas estavam antecipando o pensamento dos estudantes e dando sentido aos eventos que poderiam acontecer em sala de aula (Russ, Sherin \& Sherin, 2016). Percebe-se que os estudantes se envolveram com a tarefa, conforme a transcrição da filmagem de parte do encontro 11 (aula desenvolvida no 5. ${ }^{\circ}$ ano A), que corrobora as antecipações das professoras [8]:

[30] E1 - A equipe 4 fez a gente mais se interessar [...] Na equipe 4 dava para fazer $9+1+10$, que dá 20 . Também dá para fazer $5+5+10$, que dá 20. $E 6+4+10$, que dá $20 . E 7+3+10$, que dá 20 também.

[31] E2 - Então, cada um teve a sua forma, mas deu a mesma igualdade na resposta, só que cada um fez diferente.

[32] E3 - A conta e o valor podiam ser diferentes, mas o resultado não foi diferente, foi o mesmo. (Estudantes (1), (2) e (3), P11, 27/09/2018).

As professoras ficaram satisfeitas com as afirmações dos estudantes e, em especial, com o termo usado "deu a mesma igualdade" [31] e afirmaram que, quando surgem essas 
considerações, é possível estabelecer conexões matemáticas e sistematizar conceitos [39]. Elas refletiram sobre o episódio selecionado pela PF:

[33] M - Nossa, não é nesse momento que se pode fechar o conceito que se quer trabalhar?

[34] C - Ah, o da equivalência!

[35] M-Sim[...]

[36] $\mathrm{PF}$ - Associando às propriedades?

[37] M - Sim, já apontando as propriedades. Fechar os conceitos. Se já foi trabalhado, retomar. [...] Isso pode ser uma estratégia de fazer o contrário, né? A criança experimenta primeiro para depois concluir o conceito. Você faz a conexão entre os conceitos. A partir deste momento não seria ideal fazer um registro coletivo? Terminou esta experiência, agora vamos sistematizar.

[38] C - É, isso eu não fiz.

$[\ldots]$

[39] A - Importante é sistematizar com a linguagem matemática.

(Márcia, Celeste, Pesquisadora Formadora, Adionísia, P13, 08/10/2018).

Ademais, propuseram conexões matemáticas a partir dos apontamentos feitos pelos estudantes; logo, mobilizaram seus conhecimentos matemáticos. Ainda, conjectura-se que, quando planejam coletivamente, discutem e têm a possibilidade de refletir sobre suas ações, sentem-se encorajadas para rever o que fizeram, ou deixaram de fazer, de maneira a implementar novas estratégias, a partir das intervenções de outras professoras e reflexões pessoais [33], [34], [37], [38], [39] e [46], [47], [48], [49]. Logo, se por um lado elas imaginavam anteriormente que os alunos talvez não estabelecessem determinadas relações, por outro sentiram-se encorajadas a rever seus olhares e práticas, pois os estudantes superaram algumas de suas expectativas.

Assim, é possível compreender que tal lógica que se estabelece na sala de aula se revelou também no grupo de professores, à medida que as professoras puderam trocar experiências, discutir e compartilhar seus desafios, medos, incertezas, imprevistos, suas práticas profissionais, seus novos conhecimentos, construídos à luz das teorias (Ball \& Cohen, 1999; Serrazina, 2013).

Outro episódio semelhante deu-se em decorrência da questão que solicitava que as professoras trabalhassem na TAP 4 (Figura 5), buscando compreender a narrativa feita da aula. Neste momento do episódio, os estudantes expunham suas conjecturas relativas à tarefa matemática sobre as equipes 2 e 3 (Figura 5). Durante a TAP 3, após a escolha da tarefa matemática (Figura 2), as professoras refletiram sobre relações de equivalência que poderiam ser estabelecidas pelos estudantes. Vale ressaltar que, conforme o terceiro diálogo desta seção, as professoras enfatizaram que os estudantes iriam só calcular, sem estabelecer relações entre os números a serem completados na tabela (especificamente, referindo-se às equipes 2 e 3), apontando: "Acho dificil olharem isso [relação de equivalência]. Porque acho que vão somar as parcelas, que é a prática dele e depois vão tirar a parcela menor e tirar da maior para achar o valor desconhecido" (Celeste, D9, 19/09/2018). 
DOI: $10.20396 /$ zet.v29i00.8656716

Após a socialização de todos os grupos, atendendo ao pedido da professora Celeste, a pesquisadora/formadora escreveu na lousa parte do placar apresentado na tarefa:

\begin{tabular}{|c|c|c|c|c|}
\hline & $1^{a}$ RODADA & $2^{\text {a }}$ RODADA & $3^{\mathrm{a}}$ RODADA & TOTAL \\
\hline EQUIPE 2 & 15 & 7 & & 35 \\
\hline EQUIPE 3 & & 15 & 8 & 35 \\
\hline
\end{tabular}

Quando a pesquisadora/formadora perguntou aos estudantes se eles perceberam alguma relação entre os dados destas duas equipes. Três duplas levantaram as mãos e responderam:

A4 - "As duas equipes tiveram o 35 como total".

A2 - "Nas duas equipes uma das parcelas é o 15". $08^{\prime \prime}$.

A6 - "Em uma equipe apareceu o 7 em uma rodada e na outra

A pesquisadora/formadora perguntou se alguma dupla conseguiu perceber uma relação entre todas estas informações apontadas pelos estudantes A4, A2, A6 e os valores encontrados. Rapidamente a dupla A1 pediu a palavra. Assistam ao episódio 8 (-)

Ao final a pesquisadora perguntou: "Então, será que seria necessário efetuar os cálculos que vocês fizeram para encontrar o valor da $1^{\text {a }}$ rodada da equipe 3 ? Os estudantes responderam em coro: "não". Algumas duplas disseram que "se eles tivessem olhado para estas relações com mais atenção, teriam respondido a questão C, apenas fazendo relações, sem precisar de cálculos e prova real".

Figura 5 - TAP 4: Recortes de prática: análise e reflexões Fonte: (Barboza, 2019)

As professoras foram convidadas a analisar o que alguns dos estudantes disseram, ao socializarem suas estratégias e pensamentos matemáticos sobre o significado de "equivalente" do sinal de igualdade (Figura 5). Nesse contexto, elas assistiram ao episódio, conforme revela a transcrição de um trecho da filmagem de parte do encontro 11 (aula desenvolvida no $5^{\circ}$ ano A):

[40] E1 - Eu e o V. tínhamos percebido, que na equipe 2 tinha dado o 15 primeiro. E depois na equipe 3 tinha o 15 também. [...] E a diferença é del. O outro aluno da mesma dupla vai até a lousa e diz:

[41] E1.2 - As duas têm o mesmo resultado, e como aqui está dizendo que é 35, os dois são iguais. Podia pôr 1 a mais aqui, tipo, aqui podia ser 13, mas é 12, e aqui podia ser 12, mas é 13. É que neste aqui [apontando para o 8], tem um a mais que esse [apontando para o 7].

(Estudantes (E. 1) e (E 1.2), P11, 27/09/2018).

Uma professora afirmou, assim que viu o episódio em vídeo e ouviu a socialização do pensamento matemático dos estudantes: "Maravilhoso, eu gostei. Eles demonstraram que compreenderam, sim [a relação de equivalência do sinal de igualdade]" (Márcia, P13, $16 / 10 / 2018)$. 
É possível considerar que as professoras perceberam as estratégias matemáticas adotadas pelas crianças. Por outro lado, durante a TAP 3 (Diálogo 3), acreditavam que os estudantes não iriam atentar à equivalência, ou relação, entre as igualdades. No entanto, nos registros descritos anteriormente (Figura 5 e Diálogo 7), os estudantes demonstraram essas percepções, quando foram convidados a enunciar o que haviam percebido em relação às equipes 2 e 3 . Tais ações são apontadas por estudos que salientam que, caso uma solução pouco trivial não apareça, ela pode ser introduzida, de maneira a propiciar importantes discussões matemáticas (Stein et al., 2008).

Outro aspecto que a TAP 4 suscitava era a avaliação da forma como as crianças foram dispostas para a realização da tarefa matemática e da maneira como ela foi aplicada. Por um lado, elas ressaltaram que, ao planejar, indicaram uma leitura coletiva, e esta deveria ter sido feita pela professora, por exemplo, mas foi feita em conjunto, pela professora (C) e seus estudantes. Por outro, os estudantes apontaram no episódio analisado suas conjecturas sobre trabalhar em duplas com tarefas matemáticas:

[42] E 4 - E ainda mais que a gente fez por dupla, deu pra gente contar e ficou bem mais fácil da gente fazer as contas. [...] Dava pra fazer um monte de continhas, que vai dar o número 10. Eu estava pensando nisso, que, quando a gente junta cada vez mais pessoas, vai ficando mais interessante. A resposta vai ficando bem mais assim... inteligente.

(Estudante [5], P11, 27/09/2018).

As professoras concordavam que tarefas matemáticas realizadas em dupla são potenciais para trocas de conjecturas diferentes resoluções, verificações e aprendizagem. Evidenciaram, assim, que estavam a (re)considerar a forma como trabalham. E comentaram suas conjecturas:

[43] C - É, eu gostei. Vou fazer mais assim, pois faço bastante na área de humanas.

[44] K - Fazer em dupla tem essa troca de observar como um fez, como o outro fez.

[45] A - Mas eu costumo trabalhar na matemática em duplas, só depois que eu trabalhei o conteúdo individual. Mas as possibilidades que a gente tem quando está num trabalho em dupla ou em trio, ou em grupo e a gente possibilita que eles falem como pensaram, o que fizeram, a gente também constrói. Porque geralmente fica centrado no professor, quem tem a autonomia matemática, o detentor do conhecimento. E, quando a gente possibilita que os alunos também falem, a gente também fortalece o que os alunos pensam e são capazes de fazer e se expor.

(Celeste, Kátia, Adionísia, P14, 16/10/2018).

As professoras registraram (Figura 6) suas constatações, após reflexões sobre o trabalho em dupla, conforme tinham planejado coletivamente: 
DOI: $10.20396 /$ zet.v29i00.8656716

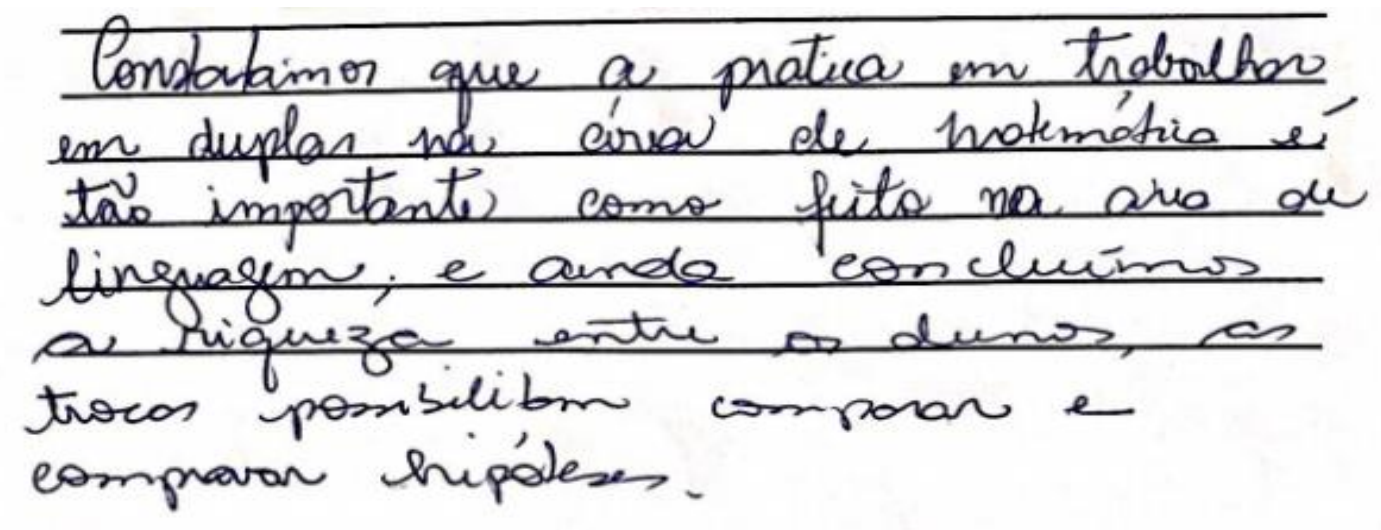

Figura 6 - Protocolo apresentado - análise do trabalho em duplas TAP 4 Fonte: Adionísia, Celeste, Kátia, Luciana, Márcia e Valdete (TAP4, 16/10/2018)

Ao afirmarem que constataram que trabalhar em dupla é importante na área da matemática, pois possibilita socialização entre os alunos e a comparação de hipóteses, as professoras estão a (re)estruturar seus conhecimentos sobre o conteúdo e os estudantes (KCS) [43], [44], [45] e (Figura 6), pois estão discutindo sobre a disposição deles. Além disso, elas mobilizam os conhecimentos matemáticos, possibilitando saber como se constroem os tópicos matemáticos, ou seja, o conhecimento do conteúdo no horizonte (HCK).

No desenvolvimento do planejamento (TAP 3), elas acordaram que a professora deveria selecionar antecipadamente quais relações poderiam ser feitas durante a plenária de socialização de respostas dos estudantes, conforme Figura 3. Porém, a professora Celeste aguardou toda a turma terminar de resolver a tarefa e propôs a socialização das estratégias usadas pelos grupos, seguindo a ordem em que estavam sentados nas fileiras, iniciando pela primeira fileira, do fim para o começo (A4, A3, A2, A1), seguida pela segunda fileira, do começo para o fim (A5, A6, A7, A8, A9). Pediu para cada grupo que contasse como e o que fez para responder às questões. Depois, atendendo à sugestão de um estudante, pediu que, mantendo a sequência, fossem à frente para ler como chegaram aos resultados. As professoras refletiram que elas haviam sugerido algo diferente e sugeriram ajustes para as futuras ações:

[46] A - Mas não seria até para comparar, quem fez adição, quem fez subtração. Não só apresentar e nem todo mundo [se referindo a todos os grupos/alunos]?

[47] C - É, poderia mesmo ter sido feito assim. Porque uma dupla teve uma prática e outra teve outra [...]

[48] A - Porque a comparação poderia ter sido feita na lousa, por estratégias, para poder discutir duas diferentes.

[49] C - Isso eu não fiz mesmo.

Fonte: Adionísia e Celeste (P13, 08/10/2018)

Posteriormente a essa proposição, as professoras registraram conjuntamente se fariam mudanças na forma como a professora Celeste propôs a plenária (Figura 7) e de que maneira poderia ser feita. 
DOI: $10.20396 /$ zet.v29i00.8656716

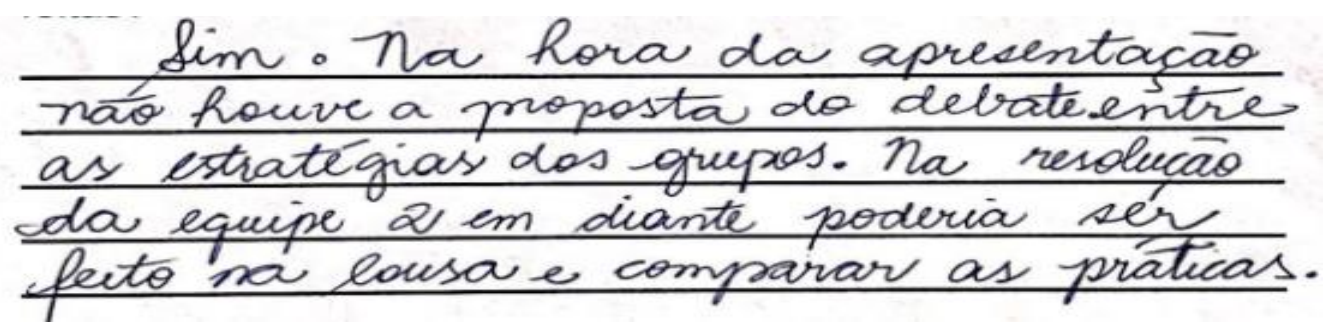

Figura 7: Protocolo apresentado - sugestões de mudanças para o desenvolvimento da aula TAP 4.

Fonte: Adionísia, Celeste, Kátia, Luciana, Márcia e Valdete (TAP4, 08/10/2018)

Assim, é possível reafirmar que as professoras estavam (re)estruturando seus conhecimentos, a partir das reflexões propostas, do olhar às práticas profissionais centradas na sala de aula (Ball \& Cohen, 1999; Silver et al., 2007), no hábito da reflexão sobre as práticas e na conscientização de que mudanças são necessárias para dar respostas aos desafios do ensino da matemática (Serrazina, 2013). Também é possível conjecturar que, durante o desenvolvimento das TAP 3 e 4, pelos excertos aqui apresentados, as professoras estavam em constante construção de seus conhecimentos matemáticos e didáticos (Ball, Thames \& Phelps, 2008).

Durante a finalização da TAP 4, ao encerrar suas reflexões, elas afirmaram que aprender e dar importância à forma como as crianças pensam é essencial. Uma delas expôs:

[50] L- O que fica para mim, é isso [...] perceber a linha de raciocínio deles [estudantes]. Porque o conhecimento é uma construção e não uma massificação [...]. Porque é assim [apontando para o slide da TAP de reflexões] que a gente também tem o retorno do nosso trabalho como professor [...]

(Luciana, P14, 16/10/2018).

Outra professora se posicionou, afirmando que as oportunidades trazidas pela pesquisadora-formadora poderiam ser algo mais constante para a formação profissional do grupo: "o que ela trouxe dá para a gente também começar a fazer aqui, as conversas, a escolha de uma aula e tarefa, pedir a colega em aula livre para filmar. Depois, vamos discutir juntas, refletir, aquela coisa do olhar do professor pesquisador" (Adionísia, P14, 16/10/2018). Essa afirmação permite conjecturar sobre a importância de processos formativos como este, pelas potencialidades reflexivas e pela possibilidade de aprendizagem profissional, pois foi despertada a pesquisa na/para a prática.

Assim, passa-se às considerações finais deste estudo.

\section{Considerações finais}

Enunciou-se como objetivo deste artigo compreender e explicar como ocorre a construção do conhecimento matemático e didático de professores que ensinam matemática nos anos iniciais, em um processo formativo sobre os diferentes significados do sinal de igualdade. Em consonância com o objetivo do artigo, acredita-se que o trabalho com TAP, as discussões que dela advêm e seu potencial de construção de conhecimentos são possibilidades para (re)pensar a formação de professores que ensinam matemática. Sobretudo, para o trabalho com diferentes significados do sinal de igualdade. 
Depreende-se das análises a mobilização de conhecimentos específicos para o ensino e sobre os estudantes, que as professoras reorganizaram, desenvolveram e construíram, ao envolver-se neste processo formativo coletivo de planejar, desenvolver e refletir sobre uma aula de matemática a respeito dos diferentes significados do sinal de igualdade, com o uso de TAP, seguido de mediações, discussões e reflexões sobre a aula.

Entende-se que as TAP, por si sós, não possibilitam (re)significar e mobilizar conhecimentos matemáticos e didáticos. Não há uma visão ingênua de que, para construção de conhecimentos, basta propor boas TAP. No entanto, é possível reconhecer a importância da reflexão do professor ao trabalhar com elas, a partir de questionamentos do formador e das discussões desencadeadas.

As professoras foram convidadas a examinar o próprio pensamento e a forma como ensinam. Assim, esta aprendizagem profissional, por meio de TAP, deu-se a partir de discussões coletivas, pois assim as trocas com outros profissionais permitiram compreender, comparar, (re)formular suas próprias (in)certezas, ampliando suas próprias oportunidades de aprender. Olharam para tarefas matemáticas e seu potencial, para as discussões coletivas reflexivas e sua importância na aprendizagem (Ball \& Cohen, 1999).

As seis professoras que colaboraram nesta pesquisa reorganizaram aspectos matemáticos, pois com propriedade citavam o significado de equivalência do sinal de igualdade, bem como a reorganização dos conhecimentos didáticos. Tais conjecturas baseiam-se no fato de que elas verbalizavam/registravam que deveriam propor tarefas matemáticas para serem resolvidas em duplas. Passaram a dar mais importância às possibilidades de resolver e antecipar o que os alunos fazem/podem fazer nas tarefas e a decidir como/o que fazer para manter as discussões matemáticas elevadas e a tarefa desafiadora. Deram importância à oportunidade de os estudantes explicarem como pensaram e à riqueza de ver que eles podem superar as expectativas de seus professores.

Logo, finalizou-se as análises, conjecturando que os excertos apresentados apontam mobilização e construção de conhecimentos, pois questões centrais foram levantadas pelas participantes: direcionar o olhar do professor ao pensamento dos seus alunos, como recurso de sua própria aprendizagem e reconhecimento de seu próprio trabalho, bem como antecipar o que os alunos são capazes de fazer (Ball, Thames \& Phelps, 2008; Russ, Sherin \& Sherin, 2016). Os excertos ainda ressaltam apontamentos das professoras sobre a importância de fazer conexões matemáticas com o conteúdo trabalhado na aula, com o que já foi feito e abrir portas ao que será trabalhado posteriormente, bem como proporcionar o trabalho em duplas e trios para propiciar discussões matemáticas. Ademais, sugeriram a possibilidade de manter hábitos de planejar coletivamente algumas aulas, pensar junto com seus pares, discutir as tarefas e a forma como podem desenvolver uma aula e posteriormente refletir sobre ela.

Os excertos apresentados corroboram estudos discutidos na revisão de literatura, bem como a possibilidade de as professoras continuarem a desenvolver novos entendimentos do pensamento dos estudantes, por meio de interações com alunos em sua própria prática letiva (Russ, Sherin \& Sherin, 2016). As professoras olharam para tarefas matemáticas e seu 
DOI: $10.20396 /$ zet.v29i00.8656716

potencial, para as discussões coletivas reflexivas e sua importância para a própria aprendizagem profissional, seja no planejamento, na seleção de tarefas ou nas reflexões sobre suas práticas (Ball \& Cohen, 1999; Serrazina, 2013; Silver et al., 2007; Smith, 2001). Corroborando Ma (1999): um processo central da aprendizagem do professor é a formação de novas estruturas de conhecimento, combinando várias de suas esferas e potencialmente algum novo conhecimento, seja individual ou coletivamente.

Não obstante, levantaram um ponto que pode servir de base a outras pesquisas, no que tange aos obstáculos enfrentados por professores dos anos iniciais com regência de todas as disciplinas (Língua Portuguesa, Matemática, História, Geografia e Ciências) e classes com superlotação de alunos. Ademais, sugerem-se pesquisas sobre a maneira como esses aspectos podem interferir nas aprendizagens profissionais de professores que continuam a aprender no exercício de suas práticas.

\section{Referências}

Ball, D. L.; Ben-Peretz, M., \& Cohen, R. B. (2014). Records of practice and the development of collective professional knowledge. British Journal of Educational Studies, 62(3), 317335.

Ball, D. L., \& Cohen, D. K. (1999). Developing practice, developing practitioners: toward a practice-based theory of professional education. In G. Sykes \& L. Darling-Hammond (Org.), Teaching as the learning profession: Handbook of policy and practice (pp. 3-32). San Francisco: Jossey Bass.

Ball, D. L., Thames, M. H., \& Phelps, G. (2008). Content Knowledge for Teaching: What makes it special? Journal of Teacher Education, Thousand Oaks, 59, 389-407.

Barboza, L. C. S. (2019). Conhecimento dos professores dos anos iniciais e o sinal de igualdade: Uma investigação com tarefas de aprendizagem profissional. Dissertação de Mestrado em Ensino e História das Ciências e da Matemática. Santo André: Universidade Federal do ABC, Brasil.

Barboza, L. C. S., Ribeiro, A. J., \& Pazuch, V. (2019). Aprendizagem profissional de professores dos anos iniciais: Explorando os diferentes significados do sinal de igualdade. Acta Scientiae, 22(4), 71-97.

Behr, M., Erlwanger, S., \& Nichols, E. (1980). How children view the equal sign. Mathematics Teaching, 92, 13-18.

Blanton, M., \& Kaput, J. (2005). Characterizing a classroom practice that promotes algebraic reasoning. Journal for Research in Mathematics Education, 36(5), p. 412-446.

Blanton, M., \& Kaput, J. (2008). Building disctrict capacity for teacher development in algebraic reasoning. In J. Kaput, D. Carraher \& M. Blanton (Org.), Algebra in the Early Grades (pp. 133-160). Nova Iorque: Lawrence Erlbaum Associates.

Brasil. (2017). Base Nacional Comum Curricular: Matemática. Brasília: MEC/SFE.

Britt, M. S., \& Irwin, K. C. (13 out. 2011). Algebraic thinking with and without algebraic representation: a three-year longitudinal study. $Z D M, 40(1)$, p. 39-53. 
DOI: $10.20396 /$ zet.v29i00.8656716

D’Ambrósio, U. (2004). Prefácio. In: M. C. Borba \& J. L. Araújo (Org.), Pesquisa Qualitativa em Educação Matemática, (pp. 11-23). Belo Horizonte: Autêntica.

Esteban, M. P. S. (2010). Pesquisa qualitativa em Educação: Fundamentos e tradições. (19. ed.). Porto Alegre: AMGH. Tradução de Miguel Cabrera.

Kieran, C. (1981). Concepts associated with the equality symbol. Educational Studies in Mathematics, 12, 317-326.

Kieran, C. et al. (2016). Early Algebra Research into its Nature, its Learning, its Teaching. Hamburg: Springer International Publishing.

MA, L. (1999). Saber e ensinar: Matemática Elementar. Lisboa: Gradiva.

O'donnell B., \& Taylor, A. (2007). A lesson plan as professional development? You've got be kidding. Teaching Children Mathematics, p. 272-278.

Opfer, V. D., \& Pedder, D. (2011, september). Conceptualizing Teacher Professional Learning. Review Of Educational Research, 81(3), 376-407.

Ponte, J. P. (2005). Gestão curricular em Matemática. In: GTI (Ed.). O professor e o desenvolvimento curricular (pp. 11-34). Lisboa: $A P M$.

Ponte, J. P., Branco, N., \& Matos A. (2009). A Álgebra no ensino básico. Ministério da Educação, DGIDC, Lisboa.

Ponte, J. P., Branco, N., Quaresma, M., Velez, I., \& Mata-Pereira, J. (2008). Perspectivas teóricas no estudo das práticas profissionais dos professores de matemática. In: Seminário de Investigação em Educação Matemática (pp. 267-279). Lisboa: SIEM.

Ponte, J. P., Oliveira, N., \& Matos A. (2002). Remar contra a maré: A construção do conhecimento e da identidade profissional na formação inicial. Revista de Educação, 2(11), $145-163$.

Ponte, J. P., Brocardo, J., \& Oliveira, H. (2003). Investigações matemáticas na sala de aula. Belo Horizonte: Autêntica.

Ponte, J. P., \& Quaresma, M. (2016). Teachers' professional practice conducting mathematical discussions. Educational Studies in Mathematics, Springer Nature, 93(1), 51-66.

Ribeiro, A. J., \& Cury, H. N. (2015). Álgebra para a formação do professor. Belo Horizonte: Autêntica.

Ribeiro, A. J., \& Ponte, J. P. (2019). Professional Learning Opportunities in a Practice-Based Teacher Education Programme about the Concept of Function. Acta Scientiae, 21(2), 4974.

Ribeiro, A. J., \& Ponte, J. P. da. (2020). Um modelo teórico para organizar e compreender as oportunidades de aprendizagem de professores para ensinar matemática. Zetetike, 28, e020027. https://doi.org/10.20396/zet.v28i0.8659072

Russ, R. S.; Sherin, B. L., \& Sherin, M. G. (2016). What constitutes teacher learning? In D. H. Gitomer \& C. A. Bell (Eds.), Handbook of Research on Teaching (pp. 391-438). Whashington, DC: American Educational Research.

São Paulo (Cidade). (2017). Currículo da Cidade: ensino fundamental - matemática. São Paulo: SME/Secretaria Municipal de Educação, PMSP. 
DOI: $10.20396 /$ zet.v29i00.8656716

Serrazina, M. L. (2013). O programa de formação contínua em matemática para professores do $1^{\circ}$ ciclo e a melhoria do ensino da matemática. Da Investigação às Práticas, 3(2), 75 97.

Serrazina, M. L. (2017). Planificação do ensino-aprendizagem da Matemática. In GTI (Ed.). A prática dos professores: planificação e discussão coletiva na sala de aula (pp. 9-32). Lisboa: $A P M$.

Shulman, L. S. (1986). Those who understand: knowledge growth in teaching. Educational Researcher, Thousand Oaks, 15(2), 4-14.

Shulman, L. S. (1987). Knowledge and teaching: foundations of the new reform. Harvard Educational Review, (57), 1-22.

Silver, E. A., Clark, L. M., Ghousseini, H. N., Charalambous, C. Y., \& Sealy, J. T. (2007). Where is the mathematics? Examining teachers' mathematical learning opportunities in practice-based professional learning tasks. Journal of Mathematics Teacher Education, Springer Netherlands, 10(4), 261-277.

Smith, M. S. (2001). Practice-based professional development for teachers of mathematics. Virgínia: NCTM.

Stacey, K. E., \& Macgregor, M. (1997). Ideas about symbolism that students bring to algebra. The Mathematics Teacher, 90(2), 110-113.

Stein, M. K., Engle, R. A., Smith, M. S., \& Hughes, E. K. (2008). Orchestrating productive mathematical discussions: Five practices for helping teachers move beyond show and tell. Mathematical Thinking and Learning, 10(4), 313-340.

Trivilin, L. R., \& Ribeiro, A. J. (2015). Conhecimento matemático para o ensino de diferentes significados do sinal de igualdade: um estudo desenvolvido com professores dos anos iniciais do ensino fundamental. Bolema, 29(51), 38-59.

Webster-Wright, A. (2009). Reframing professional development through understanding authentic professional learning. Review of Educational Research, 79(2), 702-739. 